\title{
Experimental Investigation of Fly Ash and Water Content on the Internal Friction of Concrete
}

\author{
Ivan Popov ${ }^{1,2, a^{*}}$, Ta-Peng Chang ${ }^{1, b}$, Yury Rossikhin ${ }^{2, c}$ and Marina Shitikova ${ }^{2, d}$ \\ ${ }^{1}$ Department of Civil and Construction Engineering, National Taiwan University of Science and \\ Technology, Taipei, 10603, Taiwan, R.O.C. \\ ${ }^{2}$ Research Center on Dynamics of Solids and Structures, Voronezh State Technical University, \\ Voronezh 394006, Russian Federation \\ a89042149140@mail.ru, btpchang@mail.ntust.edu.tw, cyar@vgasu.vrn.ru, dmvs@vgasu.vrn.ru
}

Keywords: Internal Friction; Viscoelastic Material; Concrete

\begin{abstract}
This paper presents the experimental results of investigation of the effects of fly ash and water content on damping of concrete. Impulse Excitation Technique has been used to measure damping of concrete at the ages of 3, 7, 14, 28 and 56 days. It was found that the more fly ash is added the higher damping at early ages is. At the age of 3 days due to addition of $10 \%, 20 \%$ and $30 \%$ of fly ash, damping of concrete is increased by $12.92 \%, 34,45 \%$ and by $49,49 \%$, respectively. At the age of 7 days the values of internal friction can be increased by $12.92 \%, 34.45 \%$ and by $49,49 \%$, accordingly, and by $12.92 \%, 34,45 \%$ and by $49,49 \%$, at 14 days. The less water is added the less valued of concrete damping are. Reducing water content by 10 and 20 liters per cubic meter, concrete damping can be decreased by $9.2 \%$ and by $27.00 \%$, at 7 days by $12.8 \%$ and by $23.6 \%$, and at 14 days by $7.4 \%$ and $17.5 \%$, respectively. After 14 days the changes of damping become less significant, which is related to concrete microstructural changes due to its hardening.
\end{abstract}

\section{Introduction}

Traditionally, in many sources of engineering literature concrete has always been considered as an elastic material [1, 2]. However, in reality it is not always true. In the previous works [3, 4] authors have discussed viscoelastic properties of concrete. As any viscoelastic material, it has complex Young's Modulus. The real part $E^{\prime}$, or Storage Modulus, represents its elastic properties, whereas the imaginary part $E^{\prime \prime}$ (Loss Modulus) characterizes its viscosity. Fresh concrete mixture is a viscoelastic substance, which has a constantly changing viscosity. During setting and hardening of concrete its elastic properties $\left(E^{\prime}\right)$ are increasing and viscosity $\left(E^{\prime \prime}\right)$ is decreasing.

It is important to understand the correlation between viscous and elastic properties of the material. For this purpose, internal friction, or damping, can be considered. There exist several approaches to introduce the definition of internal friction or damping. Blatner et al. [5] have introduced the most general definition as a dissipation of energy in a material, which is different from the term "friction" meaning the resistance against motion. Referring to cyclic loading of the material, authors have defined the specific damping capacity $\Psi$

$$
\Psi=\Delta W / W
$$

or the Loss factor $\Delta W / 2 \pi W$, and the Quality factor $Q$

$$
Q=2 \pi W / \Delta W
$$

Internal friction itself $Q^{-1}$ is introduced as [6]

$$
Q^{-1}=\Delta W / 2 \pi W
$$

Considering a viscoelastic solid under a cyclic applied stress or strain, for sinusoidal varying stress and strain 


$$
\begin{aligned}
& \sigma^{*}=\sigma_{0} e^{i \omega t} \\
& \varepsilon^{*}=\varepsilon_{0} e^{i(\omega t-\phi)}=\left(\varepsilon^{\prime}-i \varepsilon^{\prime \prime}\right) e^{i \omega t}
\end{aligned}
$$

respectively, complex modulus can be written as

$$
E^{*}(\omega)=\frac{\sigma^{*}}{\varepsilon^{*}}=E(\omega) e^{i \phi(\omega)}=E^{\prime}(\omega)+i E^{\prime \prime}(\omega)
$$

where, $\phi$ is the phase lag between stress and strain. In such a situation internals friction can be defined as $[5,6]$ :

$$
Q^{-1}=\frac{\Delta W}{W}=\tan \phi=\frac{E^{\prime \prime}}{E^{\prime}}=\frac{\varepsilon^{\prime \prime}}{\varepsilon^{\prime}}
$$

Moreover, similar formula can be derived when shear stress or strain is applied [7]:

$$
\begin{aligned}
& G^{*}=G^{\prime}+i G^{\prime \prime} \\
& Q^{-1}=\frac{G^{\prime \prime}}{G^{\prime}}
\end{aligned}
$$

where, $G^{\prime}$ is the shear-storage modulus, and $G^{\prime \prime}$ is the shear-loss modulus.

\section{Impulse Excitation Technique}

Impulse Excitation Technique (IET) is a very convenient method to identify internal friction of a material. It is based on the following concept. A weak impact is applied to a specimen, which is located on a special wire support with specific conditions. The impact causes vibrations of the sample and the signal is recorded by a microphone and transmitted to the PC software RFDA (Resonant Frequency and Damping Analyzer). Software calculates resonant frequencies and corresponding values of damping, as well as the values of Storage Elastic and Shear Moduli. According to the software algorithm, damping is calculated as:

$$
Q^{-1}=k /\left(\pi f_{r}\right)
$$

The details of IET are given in [8].

\section{Experimental Program}

In order to investigate the effect of fly ash content and water content on the concrete damping six batches of concrete have been cast for the experiment (see Table 1). Reference mixture M0 is based on ACI standard with water-to-binder ratio 0.41 and contains no any fly ash. Mixtures M10, M20 and M30 are obtained using the same standard, however, they have 10, 20 and 30 per cent, respectively, of cement replacement by Type F fly ash. They are designed to investigate the effect of fly ash on the internal friction of concrete. Mixtures M0a and M0b have all the components fixed as in the reference mixture, except water. In order to investigate the effect of water content on the concrete damping, the amount of water was reduced till $175.00 \mathrm{~kg}$ and $184 \mathrm{~kg}$ for mixtures M0a and M0b, accordingly.

For each batch of concrete two types of samples have been cast. The first one is cylindrical in shape, $200 \mathrm{~mm}$ in height and $100 \mathrm{~mm}$ in diameter. It was used to obtain standard concrete characteristics, such as compressive strength, dynamic Young's modulus, etc. Another type of specimens is a block, 160x 80x40 mm. It was designed for the internal friction test. 
Table 1. Concrete mix proportions.

\begin{tabular}{|c|c|c|c|c|c|c|}
\hline $\begin{array}{c}\text { Concrete } \\
\text { batch }\end{array}$ & $\begin{array}{c}\text { Water, } \\
\mathrm{kg}\end{array}$ & $\begin{array}{c}\text { Cement, } \\
\mathrm{kg}\end{array}$ & $\begin{array}{c}\text { Type F Fly ash, } \\
\mathrm{kg}\end{array}$ & $\begin{array}{c}\text { Fine ag., } \\
\mathrm{kg}\end{array}$ & $\begin{array}{c}\text { Coarse ag., } \\
\mathrm{kg}\end{array}$ & $\begin{array}{c}\mathrm{SP}, \\
\mathrm{kg}\end{array}$ \\
\hline M0 & 194.00 & 473.17 & 0.00 & 768.69 & 932.38 & 2.20 \\
\hline M10 & 194.00 & 425.85 & 47.32 & 749.72 & 932.38 & 2.20 \\
\hline M20 & 194.00 & 378.54 & 94.63 & 730.74 & 932.38 & 2.20 \\
\hline M30 & 194.00 & 331.22 & 141.95 & 711.76 & 932.38 & 2.20 \\
\hline M0a & 174.00 & 473.17 & 0.00 & 768.69 & 932.38 & 2.20 \\
\hline M0b & 184.00 & 473.17 & 0.00 & 768.69 & 932.38 & 2.20 \\
\hline
\end{tabular}

\section{Properties of the Materials}

The raw materials for the concrete mixtures are as follows: Cement - type I Ordinary Portland Cement (OPC), produced by Taiwan Cement Corporation (chemical composition see Table 2); water - regular tap water; fine aggregates - river sand (see Table 3); coarse aggregates - gravel (see Table 5); Superplasticizer - Type G superplasticizer, Yu-Lin Brand, produced in Taiwan ( $\mathrm{pH}=4.34$, density $1090 \mathrm{~kg} / \mathrm{m}^{3}, \mathrm{Cl}$ content $44 \mathrm{ppm}$ ).

Table 2. Cement chemical composition.

\begin{tabular}{|c|c|c|c|c|c|c|c|}
\hline \multicolumn{8}{|c|}{ Chemical composition } \\
\hline Components & $\mathrm{SiO}_{2}$ & $\mathrm{Al}_{2} \mathrm{O}_{3}$ & $\mathrm{Fe}_{2} \mathrm{O}_{3}$ & $\mathrm{CaO}$ & $\mathrm{MgO}$ & $\mathrm{SO}_{3}$ & LOI \\
\hline$\%$ & 20.42 & 4.95 & 3.09 & 61.96 & 3.29 & 2.4 & 1.75 \\
\hline
\end{tabular}

Table 3. Physical properties of fine and coarse aggregate.

\begin{tabular}{|c|c|c|}
\hline Properties & $\begin{array}{c}\text { Coarse } \\
\text { Aggregate }\end{array}$ & $\begin{array}{c}\text { Fine } \\
\text { Aggregate }\end{array}$ \\
\hline Maximal Coarse Aggregate size, $\mathrm{mm}$ & 15.0 & - \\
\hline Specific gravity $(\mathrm{OD}), \mathrm{g} / \mathrm{cm}^{2}$ & 2.70 & 2.63 \\
\hline Fineness modulus & 6.58 & 2.73 \\
\hline Water absorption, \% & 0.56 & 1.78 \\
\hline
\end{tabular}

\section{Experimental Setup}

Experimental setup for the internal friction test consists of the following components (see Figure 1): PC, RFDA basic software, microphone, a set of steel impactors and a special steel wire support, which is custom made in order to adapt standard RFDA basic device to test concrete blocks [3].

\section{Results and Discussions}

All the cylindrical specimens have been tested at the ages of 3, 7, 14 and 28 days. Compressive strength at the age of 28 days for different mix proportions is shown on Fig. 2, whence it could be observed that in the case of increase in the fly ash content from 0 up to $30 \%$ the increase in the compressive strength there is an increase of compressive strength. As it was expected, with the reduction of water amount in the mixture, the compressive strength has reached higher values.

Considering Fig. 3, two comparisons could be made. The first one considers mix proportions M0, M10, M20 and M30 and explains the effect of fly ash content on the damping of concrete. At early ages, for instance, at the age of three days, the increase in the fly ash content from 0 to 10,20 and 30 per cent leads to the increase in the internal friction by $12.92 \%, 34,45 \%$ and by $49,49 \%$, respectively. At the age of 7 days, the augmentation becomes $21,67 \%, 38,84 \%$ and $99,22 \%$, correspondingly. At 14 days, we can observe that the relative values of damping raise at $11.40 \%$, $41.6 \%$ and $47.23 \%$. 


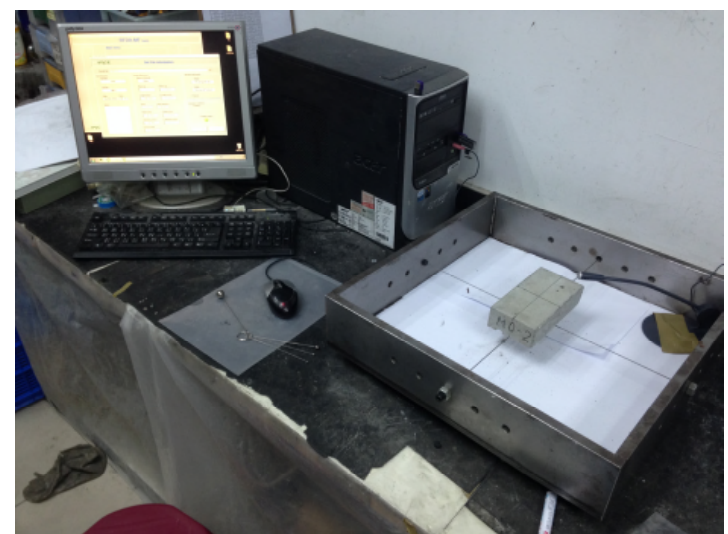

Fig. 1 Experimental setup for the internal friction test.

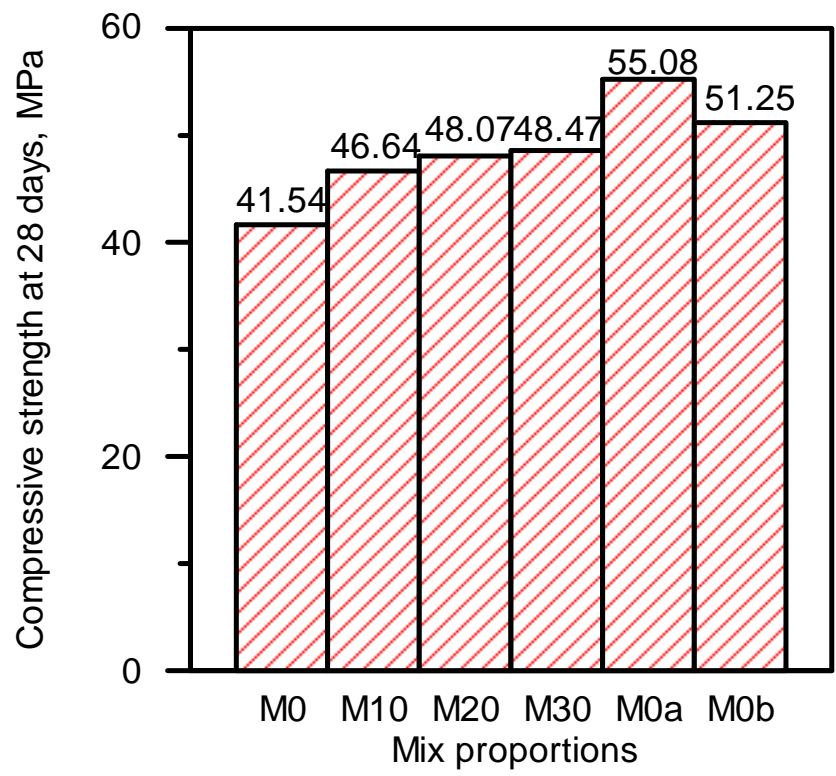

Fig. 2 Compressive strength for different mix proportions at the age of 28 days.

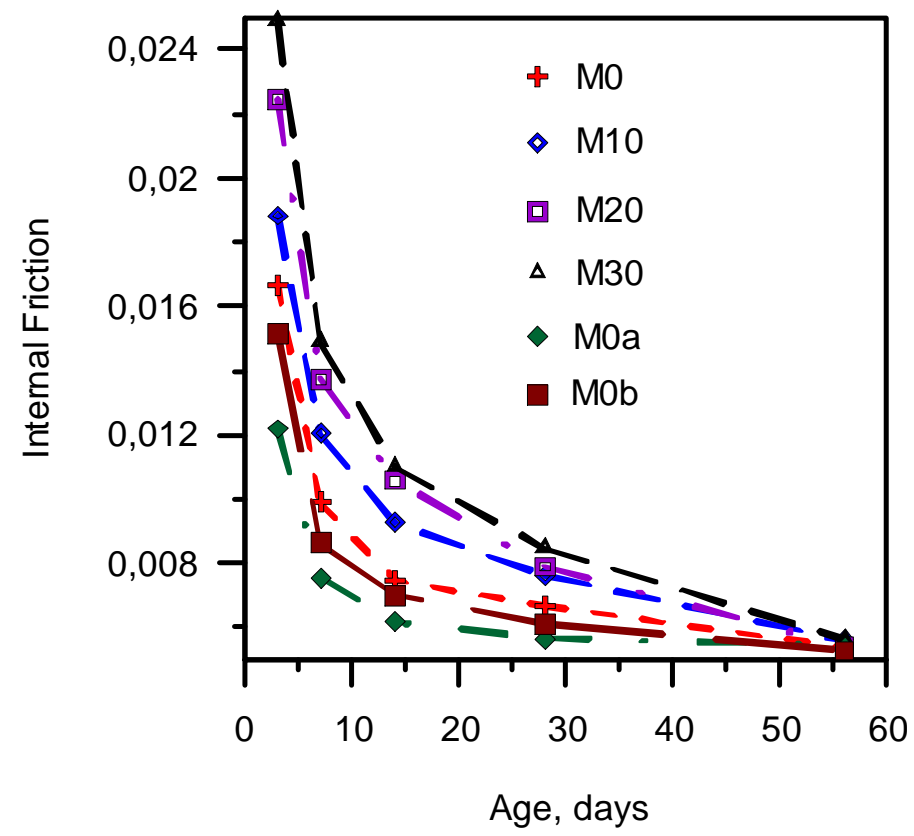

Fig. 3 Effect of fly ash and water content on the internal friction of concrete.

The second comparison shows the effect of water content on the internal friction of concrete, mixtures M0, M0a and M0b should be compared. It is obvious that the less water in the concrete 
mixture, the smaller value of damping is obtained. At 3 days the decrease in the water content by 10 and 20 liters for 1 cubic meter leads to the decrease in the concrete damping by $9.2 \%$ and by $27.00 \%$, respectively, and at 7 days by $12.8 \%$ and by $23.6 \%$, respectively. At 14 days the values become $7.4 \%$ and $17.5 \%$, accordingly.

It should be also noted that the most significant changes of internal friction occur at the ages earlier that 14 days, after that the process slows down and the changes become less significant. All of these effects could be explained by the microstructural changes in concrete due to its hardening. Raw concrete behaves more viscoelastically, and a hardened one possesses more elastic properties.

\section{Conclusions}

Based on the experimental results, the following conclusions can be made:

1) The more fly ash is added the higher damping at early ages is.

2) At the age of 3 days due to the addition of $10 \%, 20 \%$ and $30 \%$ of fly ash, the damping of concrete is increased by $12.92 \%, 34.45 \%$ and by $49.49 \%$, respectively.

3) At the age of 7 days the values of internal friction can be increased by $12.92 \%, 34.45 \%$ and by $49.49 \%$, accordingly, and by $12.92 \%, 34.45 \%$ and by $49.49 \%$, at 14 days.

4) The less water is added the less valued of concrete damping are.

5) By reducing the water content by 10 and 20 liters per cubic meter, the concrete damping can be decreased by $9.2 \%$ and by $27.00 \%$, at 7 days by $12.8 \%$ and by $23.6 \%$, and at 14 days by $7.4 \%$ and $17.5 \%$, respectively.

6) After 14 days the changes of damping become less significant, which is related to concrete microstructural changes due to its hardening.

\section{Acknowledgement}

The research was sponsored by the international joint project from the Russian Foundation for Basic Research (Grant No.14-08-92008-HHC-a) and National Science Council of Taiwan (Grant No. NSC 103-2923-E-011-002-MY3).

\section{References}

[1] V. Corinaldesi. Mechanical and Elastic Behaviour of Concretes Made of Recycled-Concrete Coarse Aggregates, Constr. Build. Mater. 24(9) (2010) 1616-1620.

[2] M. Lal Gambhir. Concrete Technology. New Delhi, India: Tata McGraw-Hill, 2004.

[3] I. I. Popov, T. P. Chang, Yu. A. Rossikhin, M. V. Shitikova. Application of Impulse Excitation Technique to Investigation of Concrete Damping and its Changes at Early Ages. International Conference on Informatics, Management Engineering and Industrial Application (IMEIA), Phuket, THAILAND: Destech Publicat Inc., (2016), pp. 339-343.

[4] I. I. Popov, T. P. Chang, Yu. A. Rossikhin, M. V. Shitikova. Study of Concrete Aging Effect on the Contact Force and the Contact Time during the Impact of an Elastic Sphere upon a Viscoelastic Beam. AER-Advances in Engineering Research. 52 (2016) 175-177.

[5] M. S. Blanter, I. S. Golovin, H. Neuhausser, H. R. Sinning. Internal Friction in Metallic Materials, Springer: Berlin Heidelberg, 2007.

[6] V. S. Postnikov. Internal Friction in Metals (In Russian). Moscow: "Metallurgy", 1974.

[7] M. Oeser. Visco-elastic modeling of virgin and asphalt binders. Computer Methods for geomechanics: Frontiers and Applications, Melbourne, (2011), pp. 313-319.

[8] IMCE RFDA Basic Manual v. 1.1, IMCE N.V., Slingerweg 52, B-3600 Genk, Belgium. 